\title{
Design and Analysis of a Novel Linear Transverse Flux Permanent Magnet Motor Using HTS Magnetic Shielding
}

\author{
Wenlong Li, Student Member, IEEE, and K. T. Chau, Senior Member, IEEE
}

\begin{abstract}
In this paper, a novel linear transverse flux permanent magnet (TFPM) motor is proposed, which can offer higher thrust force, lower cogging force and easier manufacturing than its counterpart. The key is to propose a new C-shaped TFPM motor topology with the use of HTS bulks. After deriving the expressions of cogging force and thrust force, the proposed motor can be designed with minimum cogging force and maximum thrust force. Then, by employing finite element analysis, the advantages and validity of the proposed motor are verified.
\end{abstract}

Index Terms-High-temperature superconductor, linear motor, magnetic shielding, transverse flux permanent magnet motor.

\section{INTRODUCTION}

W ITH ever increasing demand of high thrust force, the development of high-thrust linear motors has taken on an accelerated pace. For those traditional linear brushless motor topologies, such as the linear induction motor, linear switched reluctance motor and linear longitudinal flux permanent magnet (PM) synchronous motor, they can not provide the desired level of force density. In recent years, the linear transverse flux permanent magnet (TFPM) motor has become attractive, since it can inherently offer high force density [1].

Fig. 1 shows the per-phase schematic of a typical linear TFPM motor [2]. Its stator consists of U-shaped cores and windings on both sides of the translator. Its translator consists of two rows of PMs and flux concentrators with nonmagnetic material in between. The stator windings adopt a typical 3 -phase winding connection, where the terminals $\mathrm{A}$ and $\mathrm{X}$ of phase $\mathrm{A}$ are connected to the terminals of phase $\mathrm{B}$ and phase $\mathrm{C}$ accordingly.

Since their magnetic flux paths via the upper and lower U-shaped stator cores are orthogonal to the current flow of the armature winding, the magnetic loading is totally decoupled from the electric loading. Hence, the corresponding electric loading can be much higher than that of its longitudinal flux counterpart. However, this topology suffers from the drawbacks

Manuscript received October 18, 2009. First published March 29, 2010; current version published May 28, 2010. This work was supported by the Research Grants Council, Hong Kong Special Administrative Region, China, under Grant HKU 7105/07E.

The authors are with the Department of Electrical and Electronic Engineering, The University of Hong Kong, Hong Kong (e-mail: wlli@eee.hku.hk).

Color versions of one or more of the figures in this paper are available online at http://ieeexplore.ieee.org.

Digital Object Identifier 10.1109/TASC.2010.2042703

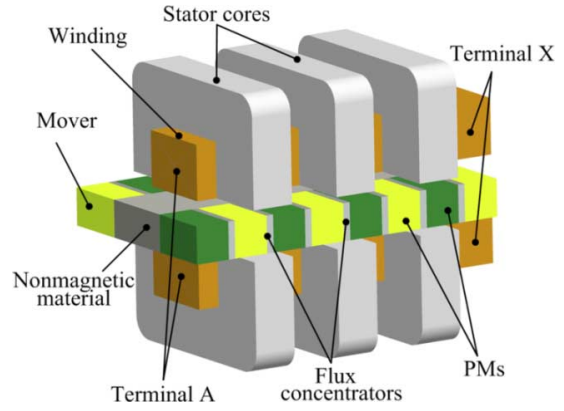

Fig. 1. Typical TFPM motor topology of phase A using U-shaped stator cores.

that it involves too many components, namely the U-shaped cores, PM segments, flux concentrators and nonmagnetic spacers, which make the structure complicated and cause manufacturing difficulty.

The purpose of this paper is to propose a new linear TFPM motor topology, which not only offers high thrust force and low cogging force, but also solves the problem of complicated structure. In addition to proposing a new motor topology and design criteria, high-temperature superconductor (HTS) bulks are employed to perform magnetic shielding [3], hence further improving the thrust force [4].

\section{MOTOR DESIGN}

\section{A. C-Shaped Stator Core}

Fig. 2 depicts the proposed C-shaped stator core of the linear TFPM motor, in which the PM mover lies between the core teeth. It can be observed that it retains the orthogonal feature between the magnetic loading and electric loading, which enables the motor to achieve high force density. Compared with the two U-shaped stator cores, the proposed C-shaped core takes the definite advantage of simple structure and hence easy manufacturing. Also, it can provide a larger cross-sectional area for armature windings, leading to further increase the electric loading and hence force density.

The dimensions of the C-shaped stator core are $w_{1}=70 \mathrm{~mm}$, $w_{2}=20 \mathrm{~mm}, w_{3}=30 \mathrm{~mm}, h_{1}=34 \mathrm{~mm}$ and $h_{2}=18 \mathrm{~mm}$. The length of each air-gap is $1 \mathrm{~mm}$. The cross-sectional area of armature windings is $320 \mathrm{~mm}^{2}$ and there are 100 turns per winding. In order to reduce the hysteresis loss and increase the permeability of the iron core, the $4 \%$ silicon-iron alloy is used to build up the stator core. Fig. 3 shows the B-H curve of this alloy. Also, in order to decrease the eddy-current loss, the stator core 


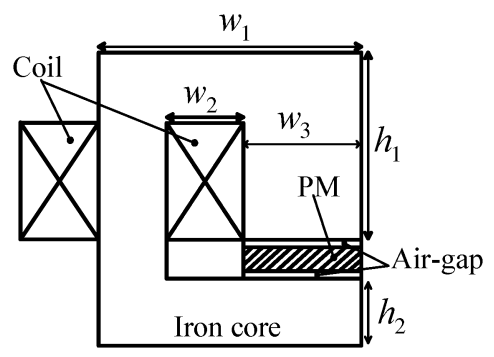

Fig. 2. C-shaped stator core.

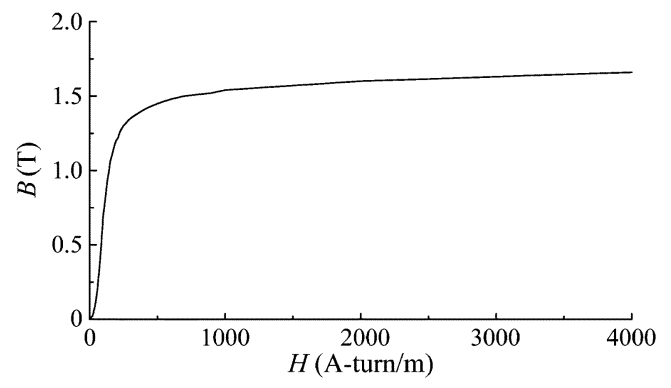

Fig. 3. $B-H$ curve of stator core.

is laminated with sheets of $0.5 \mathrm{~mm}$. The corresponding stacking factor is 0.95 .

\section{B. Cogging Force}

Cogging force is an important parameter in linear PM motors, which is caused by two effects: (i) the PM segments on the mover prefer to align with the teeth of the stator core; (ii) there are attractive forces between the ends of the stator core and the PM mover (so-called the end-effect of stator core). This cogging force causes force ripples superimposed on the thrust force, thus causing annoying jerk and vibration of the mover. Firstly, the cogging force of the proposed linear TFPM motor due to the interaction between stator teeth and PM segments can be reduced by using the technique adopted by rotational PM motors [5]. Namely, the cogging force is governed by the least common multiplier (LCM) of the number of stator slots $Q$ and the number of PM poles $p$. The larger the LCM value, the smaller the cogging force is resulted. For this design, $Q=11$ and $p=19$ are selected. Secondly, the cogging force due to the end-effect of stator core is illustrated in Fig. 4, where $F_{x 1}$ and $F_{x 2}$ are the attractive forces at the left and right ends of the stator core exerted on the PM mover, respectively. These two forces can be expressed as [6]:

$$
\begin{aligned}
& F_{x 1}=-F_{x 0}+\sum_{k=1}^{\infty} F_{k} \sin k \omega_{0} x \\
& F_{x 2}=F_{x 0}+\sum_{k=1}^{\infty} F_{k} \sin \left(k \omega_{0} x+\delta\right)
\end{aligned}
$$

where $F_{x 0}$ is the DC component, $F_{k}$ is the coefficient of the $k$-th harmonic component, $\omega_{0}=2 \pi / \tau$ is the fundamental frequency, $\tau$ is the pole pitch, $\bigcirc$ is the phase difference between $F_{x 1}$ and $F_{x 2}$. Thus, the resultant cogging force is given by:

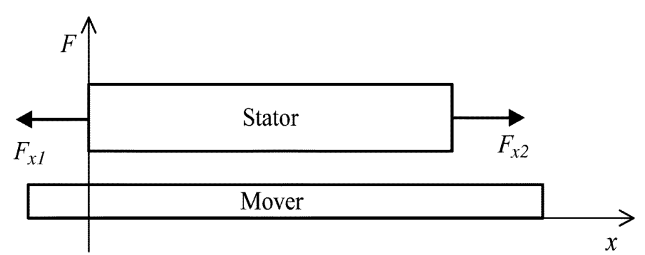

Fig. 4. Cogging force due to end-effect of stator core.

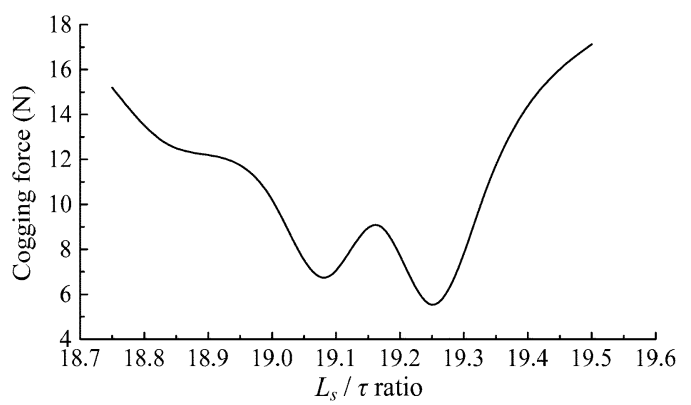

Fig. 5. Variation of cogging force with respect to physical stator length.

$$
F_{x}=F_{x 1}+F_{x 2}=\sum_{k=1}^{\infty} 2 F_{k} \sin \left(k \omega_{0} x+\frac{\delta}{2}\right) \cos \frac{\delta}{2}
$$

It can be found that $F_{x}$ will become zero if $\delta=(2 n-1) \pi$, where $n$ is an integer. Since $\delta$ is governed by the magnetic length of the stator $L_{s m}$ and $\tau$ equals $\pi$, the condition for $F_{x}=0$ can be rewritten as:

$$
L_{s m}=(2 n-1) \tau
$$

Practically, the magnetic length is not exactly equal to the physical length of the stator $L_{s}$. So, after obtaining $L_{s m}$ from (4), the optimal value of $L_{s}$ needs to be further tuned. Fig. 5 shows the relationship between $F_{x}$ and the $L_{s} / \tau$ ratio. It can be seen that the minimal cogging force is about $5 \mathrm{~N}$ occurred at the ratio of 19.25 . Therefore, when the PM pole pitch is sized as 12 $\mathrm{mm}$, the physical length of the stator is selected as $231 \mathrm{~mm}$.

\section{Thrust Force}

The principle of thrust force generation of the proposed motor can be illustrated by Fig. 6 . There are two stator teeth and an effective air-gap (including two actual air-gaps and the PM) between them. The magnetic flux generated by the armature winding flows through the air-gap from one stator tooth to another. Because of the fringing effect, there is a portion of flux passing through the air-gap beside the stator teeth. So, the thrust force $F$ exerted on the PM can be expressed as:

$$
F=F_{1}-F_{2}=\left(B_{1}-B_{2}\right) I_{p m} l_{p m}
$$

where $F_{1}$ and $F_{2}$ are the magnetic forces developed at the left and right hand sides of the PM, respectively, $B_{1}$ is the magnetic flux density under the stator teeth, $B_{2}$ is the magnetic flux in the 


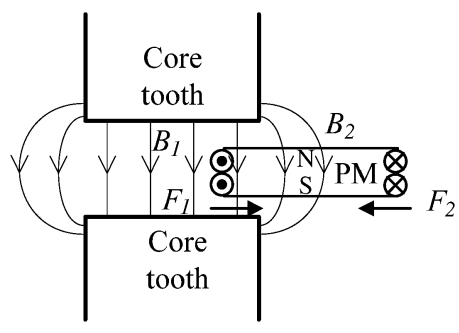

Fig. 6. Principle of thrust force generation.
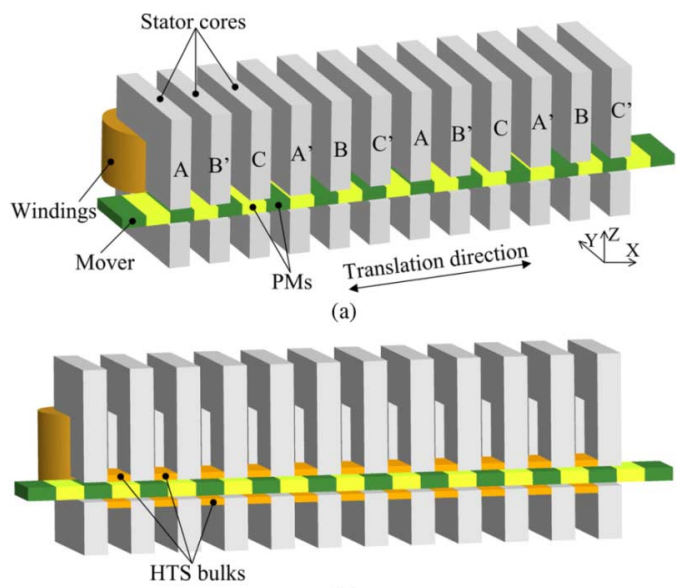

(b)

Fig. 7. Proposed motor structure. (a) Without HTS bulks. (b) With HTS bulks.

fringing areas, $I_{p m}$ is the equivalent current sheet of the PM, and $l_{p m}$ is the length of the PM. Also, $I_{p m}$ can be written as:

$$
I_{p m}=H_{c} h_{p m}
$$

where $H_{c}$ and $h_{p m}$ are the coercive force and thickness of the PM, respectively. From (5), it is obvious that the thrust force can be maximized by increasing the difference between $B_{1}$ and $B_{2}$. In order to achieve this goal, HTS bulks are inserted into the slot between the stator teeth so as to provide magnetic shielding of the fringing flux. Thus, $B_{2}$ is suppressed to almost zero while $B_{1}$ is improved, hence maximizing the difference between them.

\section{Detailed Structure}

Fig. 7 shows the detailed structure of the proposed motor with and without incorporating the HTS bulks. The stator consists of $12 \mathrm{C}$-shaped iron cores with a stack length of $10 \mathrm{~mm}$. The cores alternate with phases A, B and C, while every four of them are grouped together to form a phase. The mover is composed of 23 PM poles, in which 19 pieces are active poles. Each PM has the dimensions of $4 \times 12 \times 30 \mathrm{~mm}$ with the remanence of $1.05 \mathrm{~T}$. Each HTS bulk has the same length and width as the PM pole.

\section{MOTOR ANALYSIS}

As the proposed motor has a simple magnetic circuit in which the yoke of each stator core is equivalent to the tooth with periodic boundary, the two-dimensional (2-D) FEM is adopted for analysis. For simplification of analysis, since the HTS bulks

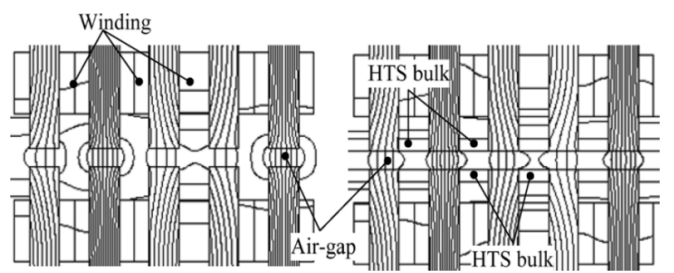

Fig. 8. Magnetic flux distributions with and without HTS bulks under armature winding excitation.

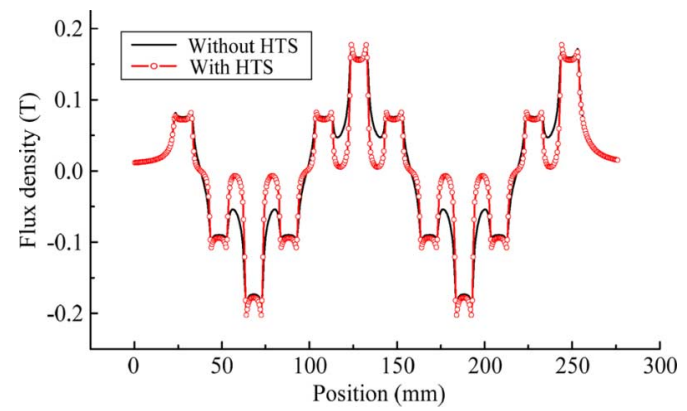

Fig. 9. Air-gap flux density waveforms with and without HTS bulks under armature winding excitation.

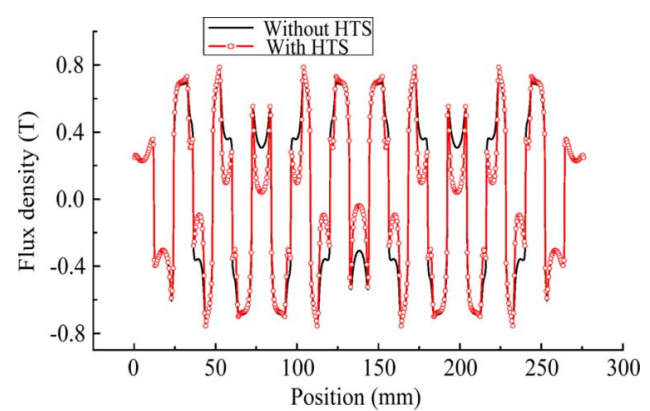

Fig. 10. Air-gap flux density waveforms with and without HTS bulks under PM excitation.

serve as flux barriers, they are considered as an ideal superconductor where the induced magnetization always opposes the field attempting to cross it. When the magnetic flux is solely excited by the armature winding with 200 A-turn, the magnetic flux distributions with and without using HTS bulks are shown in Fig. 8. It can be observed that the use of HTS bulks can effectively shield the fringing flux. The corresponding air-gap flux density is shown in Fig. 9. It can be found that the air-gap flux density under the slots is nearly zero, thus confirming the effectiveness of the HTS bulks. As shown in Fig. 9, the use of HTS bulks can shield the fringing flux which then reduces the magnitude of flux density at the positions causing force retardation. So, even though their fundamental components are essentially unchanged, the thrust force can be significantly improved. Actually, the reduction of force retardation due to the use of HTS bulks can be interpreted as the force contribution by the harmonic components of the flux density distribution.

When the magnetic flux is solely excited by the PM, the air-gap flux density is shown in Fig. 10. It further confirms that the HTS bulks can effectively shield the fringing flux, and hence improve the thrust force. Then, the no-load electromotive (EMF) waveform is deduced when the mover travels at 1 


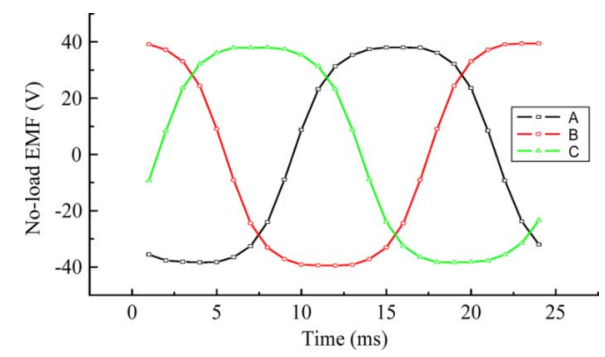

Fig. 11. No-load EMF waveforms.

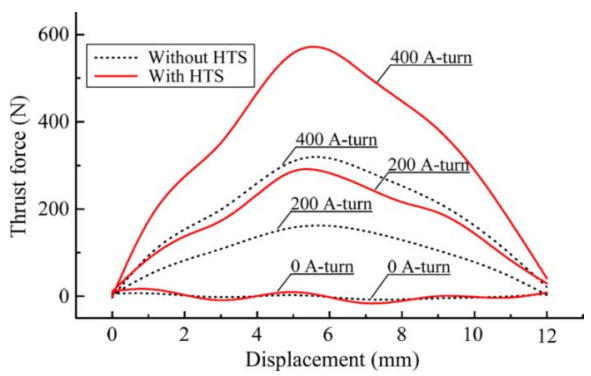

Fig. 12. Thrust force waveforms with and without HTS bulks under different armature winding excitations.

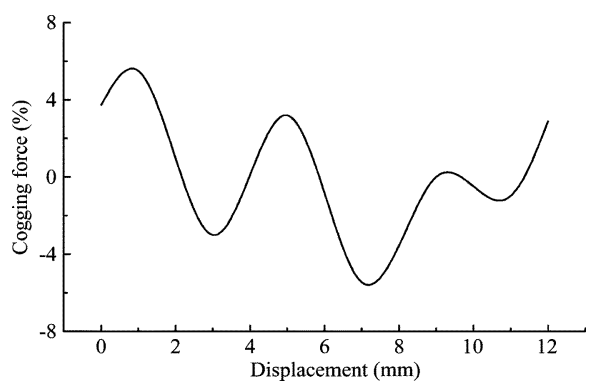

Fig. 13. Normalized cogging force waveform with HTS bulks.

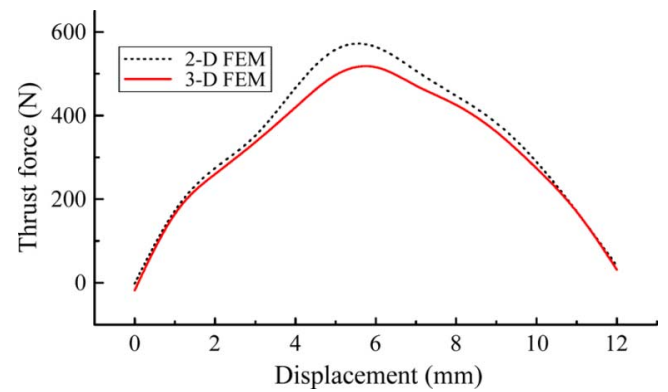

Fig. 14. Comparison of thrust force waveforms with HTS bulks using 2-D FEM and 3-D FEM.

m/s. As shown in Fig. 11, this EMF waveform is trapezoidal which enables the motor to perform brushless DC operation, hence offering higher force density than that at brushless $\mathrm{AC}$ operation [7]. Consequently, when both of the phase A and phase B windings are excited by 0 A-turn, 200 A-turn and 400 A-turn, the thrust force waveforms with and without using the HTS bulks are plotted in Fig. 12. It confirms that the peak thrust force can be improved by $175 \%$ at 200 A-turn and $183 \%$ at 400 A-turn due to the use of HTS bulks.

Although the use of HTS bulks and cooling accessories inevitably make the structure of the proposed motor become com- plicated, the resulting thrust force can be significantly improved up to almost two times. Thus, when high thrust force density is desired, this improvement can outweigh the additional complexity.

Under no excitation, the thrust force is simply due to the cogging force. Fig. 13 shows the cogging force normalized by the rated thrust force under $400 \mathrm{~A}$-turn. Although the cogging force also increases with the use of HTS bulks, the corresponding peak value is less than $6 \%$ which is actually due to the improvement of the thrust force.

Finally, in order to verify the design using the 2-D FEM analysis, the thrust force at the rated armature current excitation of 400 A-turn is also calculated by using the 3-D FEM analysis as shown in Fig. 14. It can be found that the maximum error and root-mean-square error between them are $8.7 \%$ and $4.8 \%$, respectively. However, based on a standard PC with Intel Core 2 Duo Processor $2.66 \mathrm{GHz}$ and $2 \mathrm{~GB}$ SDRAM, the computational time of the thrust force waveform using the 2-D FEM is 52 min whereas that using the 3-D FEM is 644 min (over 12 times longer time). Therefore, the 2-D FEM is preferred to the 3-D FEM for the analysis of the proposed motor design, since the corresponding errors are acceptable.

\section{CONCLUSION}

In this paper, a novel linear TFPM motor has been designed and analysed. Firstly, with the introduction of C-shaped stator cores, the motor possesses a simple structure which is easy to fabricate. Secondly, by properly selecting the numbers of stator slots and PM poles as well as tuning the physical stator length, the cogging force can be significantly suppressed to less than $6 \%$. Thirdly, by using the HTS bulks to perform magnetic shielding, the rated thrust force can be significantly improved by $183 \%$. Therefore, the proposed motor is very promising for those applications desiring high thrust force, low cogging force and easy to manufacture such as industrial linear actuators and vehicular linear drives. The prototyping details and experimental results of the proposed motor are equally important, which will be given in another paper.

\section{REFERENCES}

[1] J. Wang, K. T. Chau, J. Z. Jiang, and C. Yu, "Design and analysis of a transverse flux permanent magnet machine using three dimensional scalar magnetic potential finite element method," Journal of Applied Physics, vol. 103, no. 7, pp. 7F107:1-7F107:3, Jan. 2008.

[2] H. Weh, H. Hoffman, and J. Landrath, "New permanent magnet excited synchronous machine with high efficiency at low speeds," in Proc. Int. Conf. Electrical Machines, Pisa, Sep. 1988, pp. 35-40.

[3] J. Kvitkovic, J. Voccio, and S. Pamidi, "Shielding of AC magnetic fields by coils and sheets of superconducting tapes," IEEE Trans. Applied Superconductivity, vol. 19, no. 3, pp. 3577-3580, June 2009.

[4] D. H. Kang, Y. H. Jeong, and M. H. Kim, "A study on the design of transverse flux linear motor with high power density," in Proc. IEEE Int. Symp. Industrial Electronics, Pusan, Jun. 2001, pp. 707-711.

[5] S. Niu, K. T. Chau, and C. Yu, "Quantitative comparison of doublestator and traditional permanent magnet brushless machines," Journal of Applied Physics, vol. 105, no. 7, pp. 7F105:1-7F105:3, Apr. 2009.

[6] M. Inoue and K. Sato, "An approach to a suitable stator length for minimizing the detent force of permanent magnet linear synchronous motors," IEEE Trans. Magn., vol. 36, no. 4, pp. 1890-1893, Jul. 2000.

[7] K. T. Chau, C. C. Chan, and C. Liu, "Overview of permanent-magnet brushless drives for electric and hybrid electric vehicles," IEEE Trans. Industrial Electronics, vol. 55, no. 6, pp. 2246-2257, Jun. 2008. 